\section{Curso precongreso}

\section{Interpretación del perfil fosfocálcico}

\section{Henry Mauricio Arenas Quintero}

Endocrinólogo, Pereira.

T a homeostasis del calcio y fósforo está estrechamente reLgulada por el manejo renal, intestinal y óseo de estos elementos.

Calcio: Número atómico 20, Valencia 2, Estado de oxidación +2, Masa atómica (g/mol) 40,08. El 99\% del total del calcio del organismo se encuentra en el hueso. El 1\% restante es rápidamente intercambiable entre el espacio intra y extracelular.

\begin{tabular}{|c|c|}
\hline \multicolumn{2}{|c|}{ CALCIO } \\
\hline $\begin{array}{l}\text { EXTRACELULAR } \\
\text { Funciones: } \\
\text { - Mineralización ósea } \\
\text { - Coagulación sanguínea } \\
\text { - Excitabilidad de membrana }\end{array}$ & 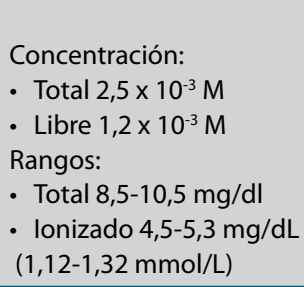 \\
\hline $\begin{array}{l}\text { INTRACELULAR } \\
\text { Funciones: } \\
\text { - Activación neuronal } \\
\text { - Secreción hormonal } \\
\text { - Contracción muscular }\end{array}$ & $\begin{array}{l}\text { Concentración: } \\
\text { - Total } 10^{-7} \mathrm{M}\end{array}$ \\
\hline
\end{tabular}

En el plasma circula en diferentes formas, el calcio plasmático está unido a proteínas y en complejos y $45 \%$ se encuentra en forma ionizada o libre (ver tabla 2).

\begin{tabular}{|c|c|}
\hline Tabla 2. & \\
\hline lonizado $45 \%$ & \multirow{2}{*}{ Ultrafiltrable } \\
\hline Complejo con fosfato, citrato y bicarbonato $10 \%$ & \\
\hline Unido a albúmina $37 \%$ & \multirow{2}{*}{ Unido a proteínas } \\
\hline Unido a globulinas $8 \%$ & \\
\hline
\end{tabular}

En la práctica clínica de rutina se mide el calcio total que representa todas las formas de calcio, se prefiere la medición del calcio ionizado o libre en pacientes con hipoalbuminemia, con desórdenes ácido-base y renales crónicos.

Perla:

$\mathrm{mmol} / \mathrm{L}=[\mathrm{mg} / \mathrm{dl} \times 10] \div$ peso molecular

$\mathrm{mEq} / \mathrm{L}=\mathrm{mmol} / \mathrm{L} \times$ valencia

\section{Hipercalcemia}

Se define como calcio total mayor de $10,5 \mathrm{mg} / \mathrm{dl}$ o ionizado $>1,35 \mathrm{mmol} / \mathrm{L}$

Severidad: leve $(10,5-12,5 \mathrm{mg} / \mathrm{dl})$, moderada $(12,5-14,5$ $\mathrm{mg} / \mathrm{dl})$ y grave $(>14,5 \mathrm{mg} / \mathrm{dl})$

\section{Principales causas de hipercalcemia}

$90 \%$ de las causas de hipercalcemia se deben a hiperparatiroidismo y malignidad.

\section{Neoplasias}

Carcinoma broncogénico 35\%, carcinoma de mama 25\%, linfomas. Mieloma $14 \%$, cabeza-cuello $8 \%$, carcinoma renal $3 \%$, carcinoma de próstata $3 \%$, carcinoma de origen desconocido $4 \%$, otros $8 \%$

\section{Fármacos \\ Diuréticos tiazídicos, litio, teriparatida, hipervitaminosis A, teofilina}

\section{Otros}

Hiperparatiroidismo primario, intoxicación por vitamina $D$, sarcoidosis, hipocalcemia hipocalciúrica familiar, síndrome lechealcalinos, inmovilización, osteoporosis, enfermedad de Paget ósea, hipertiroidismo, nutrición parenteral, enfermedad de Addison, feocromocitoma, acromegalia.

\section{Enfoque de la hipercalcemia}

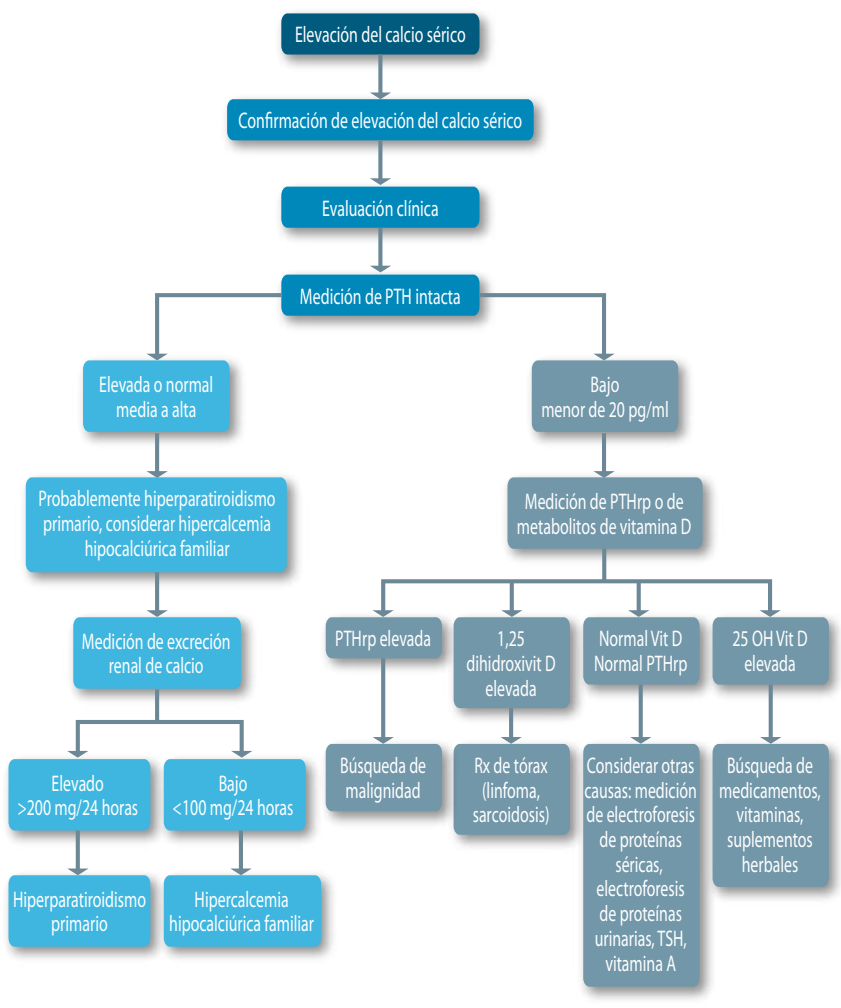




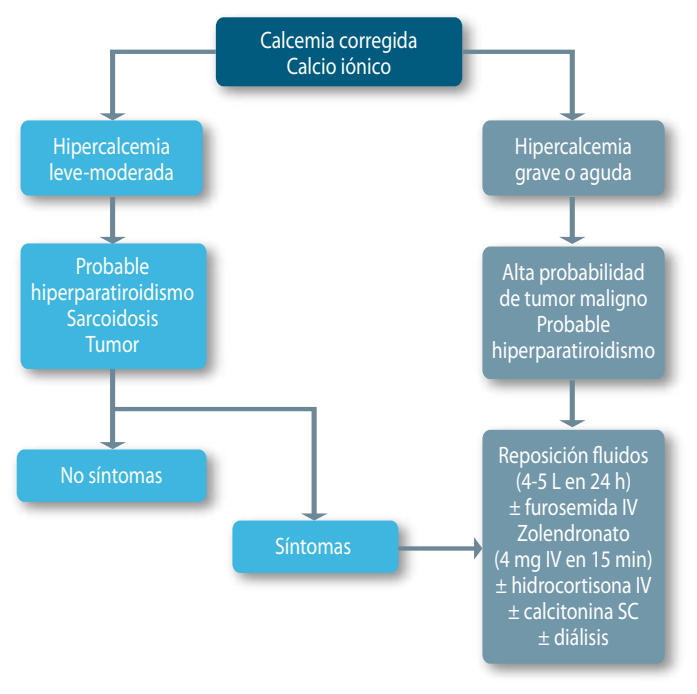

\section{Hipocalcemia}

La hipocalcemia tiene múltiples causas. Las más comunes son el hipoparatiroidismo (o la resistencia a PTH) de diferentes etiologías y el déficit de $1,25-(\mathrm{OH})_{2}$ vitamina $\mathrm{D}_{3}$ o de su acción. La insuficiencia renal crónica se asocia con hipocalcemia secundaria a alteración del metabolismo de la vitamina $\mathrm{D}$ y a absorción baja de calcio a nivel intestinal, retención de fosfato, anormalidades en proteínas séricas, resistencia a PTH y/o a toxicidad por aluminio. La deficiencia severa de magnesio produce una alteración en la secreción de PTH con subsecuente hipoparatiroidismo funcional. La pancreatitis aguda se asocia a hipocalcemia por secuestro de calcio por ácidos grasos libres. La rabdomiólisis aguda causa hipocalcemia por liberación de fosfato intracelular. Las enfermedades agudas severas también se asocian a hipocalcemia mutifactorial. El curso de los tratamientos de hipercalcemia también puede desencadenar disminución de los niveles séricos de calcio, principalmente por uso de bifosfonatos.

\section{Etiología de la hipocalcemia}

\begin{tabular}{|c|c|c|c|c|c|c|c|}
\hline & PTH & $\begin{array}{l}\text { Calcio sérico } \\
\text { corregido }\end{array}$ & $\begin{array}{l}\text { Fósforo } \\
\text { sérico }\end{array}$ & $\begin{array}{l}\text { Magnesio } \\
\text { sérico }\end{array}$ & 25-OH vit D & $\begin{array}{l}1,25-(O H)_{2} \\
\text { vit } D_{3}\end{array}$ & Creatinina \\
\hline Hipoparatiroidismo & Baja & Bajo & Elevado & Normal & Normal & $\begin{array}{c}\text { Normal o } \\
\text { baja }\end{array}$ & Normal \\
\hline $\begin{array}{l}\text { Mutaciones activadoras del } \\
\text { receptor sensor de calcio }\end{array}$ & $\begin{array}{c}\text { Normal o } \\
\text { baja }\end{array}$ & Bajo & Elevado & Normal & Normal & Normal & Normal \\
\hline Hipomagnesemia & $\begin{array}{c}\text { Normal o } \\
\text { baja }\end{array}$ & Bajo & Normal & Bajo & Normal & Normal & Normal \\
\hline $\begin{array}{l}\text { Resistencia a PTH } \\
\text { (pseudohipoparatiroidismo) }\end{array}$ & Elevada & Bajo & Elevado & Normal & Normal & Normal & Normal \\
\hline Deficiencia de vit D & Elevada & $\begin{array}{l}\text { Normal o } \\
\text { bajo }\end{array}$ & Bajo o normal & Normal & Bajo & Normal o alta & Normal \\
\hline Enfermedad renal crónica & Elevada & Bajo & Elevado & $\begin{array}{c}\text { Elevado o } \\
\text { normal }\end{array}$ & $\begin{array}{l}\text { Normal o } \\
\text { bajo }\end{array}$ & Baja & Elevada \\
\hline
\end{tabular}

\section{Tratamiento}

La meta es controlar los síntomas con el mínimo de complicaciones posibles. En pacientes con síntomas agudos, dar tratamiento con infusión endovenosa de gluconato de calcio. Inicialmente, bolo de 1 a $2 \mathrm{~g}$ de gluconato de calcio diluido en $50 \mathrm{ml}$ de dextrosa al 5\% para pasar en 10 a 20 minutos, con monitorización clínica y electrocardiográfica del paciente. Esta dosis elevará los niveles de calcio durante 2 a 3 horas, por lo tanto, en pacientes con hipocalcemia persistente, el bolo debe seguirse de una infusión lenta de gluconato de calcio. Esta última puede prepararse añadiendo 10 ampollas de calcio elemental a 1 litro de dextrosa al 5\% en agua, para infundir a una tasa máxima de $3 \mathrm{mg} / \mathrm{kg} /$ hora. La mayoría de los pacientes requieren infusiones de 0,5-1,5 mg/kg/hora. Se prefiere por catéter venoso cen- tral por el alto riesgo de irritación de los tejidos vecinos, si hay extravasación. Se debe medir calcio ionizado inicialmente cada 1-2 horas mientras se ajusta la infusión para conseguir niveles de calcio sérico en el límite inferior de normalidad y mientras la condición clínica del paciente se torna estable y luego cada 4 a 6 horas. Iniciar terapia oral con calcio y vitamina D lo más pronto posible. La infusión endovenosa debe disminuirse lentamente en un periodo de 24 a 48 horas, mientras se ajusta la terapia oral.

En pacientes con hipoparatiroidismo es esencial el manejo con calcitriol dosis de 0,25 a 0,5 mcg 2 veces al día. Los diuréticos tiazídicos se pueden usar para disminuir o prevenir la hipercalciuria causada por la terapia con calcio y vitamina D. La hiperfosfatemia se puede manejar disminuyendo el aporte de fósforo de la dieta y usando quelantes de fósforo. 


\section{Curso precongreso}

\section{Hiperparatiroidismo primario: enfoque quirúrgico}

\author{
Carlos Simón Duque Fisher
}

Otorrinolaringólogo especialista en cirugía de cabeza y cuello.

Medellín.

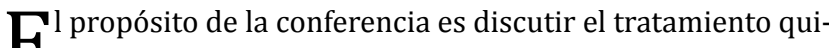
Eúrgico del hiperparatiroidismo primario. Se discutirá brevemente el proceso de diagnóstico y estudio del paciente con el fin de lograr localizar de forma preoperatoria un probable adenoma paratiroideo. De igual manera, se buscará exponer las formas de abordaje (abierto vs. endoscópico/mínimamente invasivo, cirugía radioguiada).

Se debatirá la necesidad de medir hormona paratiroidea pre, intra o posoperatoria, al igual que las complicaciones de la cirugía y el cuidado posterior a la cirugía, ambulatorio u hospitalizado.

\section{Controversias}

\section{Después de bisfosfonatos ¿qué medicamentos utilizamos?: teriparatida}

\section{Roberto Franco Vega}

Endocrinólogo

Profesor Asociado Universidad Nacional de Colombia

Director Programa Curricular Endocrinología

I os bisfosfonatos son los medicamentos más ampliamente Lusados para el tratamiento de la osteoporosis, su eficacia antifractura está ampliamente comprobada y varía de acuerdo con la formulación utilizada y el sitio esquelético estudiado. Su mecanismo de acción se basa en la inhibición de la actividad osteoclástica, por este mecanismo incrementan la densidad mineral ósea. Sin embargo, y con cierta frecuencia, como lo diremos a continuación, nos vemos obligados a suspenderlos o remplazarlos.

En los diferentes ensayos controlados, los bisfosfonatos han demostrado una reducción en el riesgo de fractura vertebral del 30\% al 70\% y de fractura de cadera entre el $40 \%$ y el 50\%. Lastimosamente, el uso prolongado de esta familia de moléculas (durante más de 5 años), se ha asociado con una supresión agresiva del remodelamiento óseo, lo cual podría causar lesiones óseas. Las dos lesiones óseas asociadas con el uso prolongado de bisfosfonatos son: osteonecrosis de mandíbula (definida como hueso necrótico expuesto en la región maxilo- facial, que no cura después de 6 a 8 semanas) y las fracturas diafisiarias y subtrocantéricas del fémur (también llamadas fracturas atípicas), se calcula que con el uso prolongado de bisfosfonatos, el riesgo de padecer estas fracturas se incrementa cerca del $0,35 \%$. Sin embargo, debemos contrastarlos con la importante reducción en las fracturas típicas.

En la práctica clínica, con frecuencia nos encontramos con pacientes que han recibido bisfosfonatos durante más de cinco años, quienes en el seguimiento clínico y evaluando la densidad mineral ósea, persisten con un riesgo aumentado de fractura. Por tal motivo, el médico se enfrenta al dilema de prolongar el tratamiento, corriendo el riesgo asociado al uso prolongado, o suspenderlo, confiando que persista la protección del bisfosfonato o administrarle otra familia de medicamentos.

Adicionalmente, existe otro motivo para administrarles otra familia de medicamentos a pacientes con osteoporosis, quienes venían recibiendo bisfosfonatos y es la llamada falla al tratamiento antiosteoporosis, definido recientemente por la IOF (International Osteoporosis Foundation), con los siguientes criterios:

1. Dos o más incidentes de fractura por fragilidad.

2. Un incidente de fractura y marcadores de recambio óseo elevados basalmente sin una reducción significativa durante el tratamiento o una mejoría significativa en la densidad mineral ósea.

Para todas las situaciones clínicas mencionadas anteriormente, la mayoría de las asociaciones que estudian enfermedades óseas y los trastornos del metabolismo óseo proponen que estos pacientes deban recibir después del tratamiento con bisfosfonatos, teriparatida.

Teriparatida es una fórmula recombinante del PTH endógena, guarda la secuencia 1-34 N terminal de la PTH, tiene todas las propiedades biológicas de la PTH intacta, esto es que interactúa con receptores para PTH en el hueso; su administración en forma intermitente estimula la formación de hueso por parte de los osteoblastos, incrementa la tasa de modelación y remodelación ósea, incrementa el grosor de la cortical, restaura la estructura del hueso trabecular, aumentando tanto el volumen como la conectividad de las trabéculas: por todo lo anterior podemos afirmar que teriparatida es el único anabólico óseo puro.

En los últimos cuatro años se han publicado algunos estudios (OPTAMISE y EUROFORS) que muestran respuesta positiva, significativa en la densidad mineral ósea en los pacientes que habían recibido bisfosfonatos y posteriormente se les administro teriparatida, especialmente a nivel lumbar, adicionalmente se encontró un aumento significativo en la rigidez y resistencia. El tratamiento con teriparatida aumentó en cerca de 30\% la resistencia ósea para diferentes cargas.

A pesar de los promisorios resultados de los estudios anteriores, no encontramos aún reportes definitivos que demuestren una reducción en la tasa de fracturas. Entendemos que estos estudios requieren un número importante de pacientes y un tiempo prolongado de observación. Estamos a la espera de los resultados de algunos de ellos. 


\section{Controversias}

\section{Bisfosfonatos: terapia intermitente}

\author{
Adriana Medina Orjuela
}

Médica Internista-Endocrinóloga

Hospital de San José, Bogotá.

$\mathrm{M}$ ientras la eficacia y relativa seguridad de los aminobisfosfonatos ha sido establecida en los estudios clínicos, ha habido algunos datos de que el uso prolongado de estos medicamentos podría incrementar el riesgo de eventos adversos raros, pero serios, como es el caso de la osteonecrosis mandibular o las fracturas atípicas que no siempre son atribuidas al medicamento; sin embargo, es mayor el beneficio del tratamiento que el riesgo, dada la baja prevalencia de estas complicaciones.

Según una revisión de Medline, desde el 31 de diciembre de 2012, la mayoría de la evidencia citada respecto a los bisfosfonatos como terapia intermitente o prolongada es nivel II.

Los bisfosfonatos tienen una característica única que los diferencia de los demás tratamientos antirresortivos y es la afinidad por el tejido óseo, lo cual determina su prolongada permanencia en el hueso después de descontinuarlo. Aquellos con más alta afinidad ósea (zoledronato, alendronato, ibandronato, risedronato y etidronato, en orden de afinidad), tienen mayor permanencia en el esqueleto y después de descontinuarlos su acción farmacológica residual persiste muchos años.

Tanto en el estudio FLEX (extensión a 10 años con alendronato), como en el HORIZON (extensión a 6 años con ácido zoledrónico), no hubo diferencias significativas en la reducción del riesgo de fracturas, excepto para fracturas vertebrales clínicas en el primero y para fracturas vertebrales radiológicas en el segundo. Basándose en esto, se considera que los pacientes de alto riesgo de fractura no serían candidatos a vacaciones de bisfosfonatos (holiday bisphosphonates), sino los de bajo y moderado riesgo.

Los bisfosfonatos pueden permanecer en el hueso después de 3-5 años de tratamiento durante 10 años. El estudio de Papapoulus y Cremers, en 2007, mostró que los sitios de unión del esqueleto de los bisfosfonatos son insaturables, por lo tanto se acumulan en un periodo de tiempo y continúan siendo liberados durante meses o años, a pesar de haber suspendido el tratamiento. A esto se le atribuye el efecto persistentemente protector de los bisfosfonatos después de suspendida la terapia.

Las guías de la AACE sugieren unas vacaciones de bisfosfonatos después de 4-5 años de tratamiento para pacientes de riesgo moderado o bajo y después de 10 años de tratamiento con bisfosfonatos para pacientes de riesgo alto.

La American Society for Bone and Mineral Research (ASBM) recomendó que el uso continuo o intermitente de bisfosfonatos más allá de cinco años se debe hacer según una revaluación anual con factores tales como DMO, principalmente en cadera y por historia de fracturas.

Es importante definir alto riesgo de fractura en los pacientes, pues McClung et al. recomiendan que los pacientes sin alto riesgo de fractura son candidatos a drug holiday y no se recomienda para aquellos con historia de fractura por fragilidad.

Cuando se reinicia el tratamiento después de las vacaciones, debe hacerse una evaluación completa y estimar el riesgo de fractura a 10 años. No hay evidencia en cuanto a qué terapia usar después del tratamiento con bisfosfonatos y debe medirse DMO cada 2-3 años y hacer seguimiento con marcadores de recambio.

El juicio clínico determinará qué pacientes son candidatos a terapia intermitente o continua con bisfosfonatos.

El beneficio obtenido con el tiempo estipulado por los estudios pivotales es suficiente para obtener eficacia antifractura en un tiempo prolongado; sin embargo, si el paciente es de alto riesgo y se evalúan parámetros de progresión bioquímicos, densitométricos o clínicos, se debería considerar uso de otra terapia que aporte igual o mayor efecto antifractura que la anterior.

\section{Controversias en osteoporosis Después de bisfosfonatos ¿qué medicamentos utilizamos? Denosumab}

\section{Amanda Páez Talero}

Endocrinóloga, Hospital Central de la Policía Nacional

G $n$ ausencia de estudios comparativos frente a frente que E permitan comparar la eficacia de las diferentes terapias para la osteoporosis, la elección de la medicación debe hacerse en forma individual, basados en la eficacia, seguridad, costo y conveniencia de los diferentes medicamentos. La mayoría de guías clínicas recomiendan a los bisfosfonatos como la primera línea de tratamiento de la osteoporosis; sin embargo, la duración, intolerancia frecuente y pobre adherencia al tratamiento, llevan a una falla terapéutica, con el deterioro de la densidad mineral ósea y aparición de fracturas. En estas condiciones debe evaluarse el cambio a otro tipo de medicamentos.

El denosumab es un anticuerpo monoclonal humano dirigido contra el receptor activador del RANK-L; bloquea la interacción del RANK-L con su receptor RANK que produce activación, migración y diferenciación de las células hematopoyéticas precursoras del linaje osteoclástico. Con este bloqueo disminuye la formación de osteoclastos, la resorción ósea, incrementa la densidad del hueso y reduce el riesgo de fractura.

\section{¿Qué sabemos?}

El efecto sobre el incremento de masa ósea con denosumab fue demostrado en el estudio FREEDOM, en $7.869 \mathrm{mu}-$ jeres posmenopáusicas con osteoporosis, mostró a tres años incremento de DMO de 9,2\% vs. $0 \%$ en columna lumbar y del $4,0 \%$ vs. $-2,0 \%$ en cadera total, en comparación con el grupo 
placebo, con reducción de marcadores de recambio óseo, y en su extensión a seis años, ganancia adicional de masa ósea de $4,9 \%$ en columna y de 1,8\% en cadera y una reducción de fracturas vertebrales nuevas de 2,3 con denosumab vs. 7,2 en el grupo placebo y en cadera de 0,7 vs. 1,2 .

Denosumab ha mostrado ser efectivo en mujeres posmenopáusicas previamente tratadas con bisfosfonatos. Braun JP y cols. demostraron que en 1.189 mujeres aleatorizadas a denosumab parenteral ( $60 \mathrm{mg}$ SC cada 6 meses ) o alendronato oral (70 mg semanales VO) la ganancia de masa ósea en columna lumbar fue de $3,5 \%$ vs. $2,6 \%$ y en cadera de $5,3 \%$ vs. $4,2 \%$ a favor de denosumab. Recknor y colaboradores; comparan denosumab e ibandronato en pacientes tratadas previamente con bisfosfonato oral diario o semanal (promedio 17 meses), al año se demostró una ganancia significativamente mayor para el grupo de denosumab de $4,2 \%$ vs. $2,0 \%$ en columna lumbar, $1,7 \%$ vs. $0,7 \%$ en cuello de fémur y $2,3 \%$ vs. $1,1 \%$ en cadera total. Kendler DL y colaboradores, realizaron un estudio en mujeres previamente tratadas con alendronato; las cuales fueron aleatorizadas a recibir denosumab o a continuar con alendronato, en la evaluación al año hubo una ganancia de masa ósea leve pero significativa, en el grupo de denosumab frente al de alendronato. En columna lumbar 3,0\% vs. 1,8\% y en cadera total $1,9 \%$ vs. 1,0\%. En estos estudios no se evaluó riesgo de fractura.

Denosumab es en general bien tolerado; sin embargo, los datos de seguridad a largo plazo aún no están disponibles. Los efectos colaterales incluyen hipocalcemia, rara en pacientes con función renal normal; en los pacientes en diálisis debe controlarse estrictamente el nivel de calcio antes de su aplicación. Supresión del remodelado óseo: Se han reportado cuatro casos de osteonecrosis de mandíbula en el estudio FREEDOM y un caso de fractura atípica de fémur después de seis dosis; también mayor frecuencia de infecciones.

\section{¿Qué no sabemos?}

No existen estudios frente a frente para comparar el efecto de denosumab vs. teriparatida, después del uso prolongado de bisfosfonatos, por lo tanto, la elección del medicamento debe centrarse en lo que sabemos respecto a los mecanismos de acción, eficacia antifractura, contraindicaciones para el uso de cada uno de ellos y al análisis de sus efectos secundarios a corto y largo plazo.

Con base en estas premisas, el denosumab debe tenerse en cuenta en las siguientes condiciones:

1. Mujeres con osteoporosis posmenopáusica con alto riesgo de fractura que han presentado intolerancia o no respuesta a bisfosfonatos orales o parenterales.

2. Dado que denosumab no se elimina a través del riñón, se recomienda su uso en pacientes con IRC con filtración glomerular < a $35 \mathrm{cc} /$ minuto, ya que no requiere ajustes de dosis; siempre y cuando se hayan corregido previamente niveles de calcio y vitamina D3 por el riesgo de hipocalcemia.

3. Se recomienda el uso de denosumab en hombres con carcinoma de próstata que van a ir a terapia de deprivación androgénica, hayan o no tenido uso previo de bisfosfonato.
4. En mujeres con cáncer de seno y osteopenia demostrada que vayan a recibir terapia con inhibidores de aromatasa.

5. En metástasis óseas, denosumab demostró ser tan efectivo como el ácido zoledrónico, para reducir el riesgo de fractura, dolor e hipercalcemia.

\section{Controversias}

\section{¿Es útil el FRAX para mi paciente?,} no Doly Nubia Pantoja Guerrero

Endocrinóloga, Pasto.

$\mathbf{C}^{\mathrm{l}}$ propósito de esta revisión es discutir por qué el cálculo del riesgo de fractura con FRAX, en la práctica clínica en Colombia, puede no ser de gran utilidad para la toma de decisiones clínicas de tratamiento, esto ante la existencia en la actualidad de otras herramientas menos dispendiosas para tal fin.

Entre los factores que deben tenerse en cuenta para soportar esta afirmación es que los algoritmos para definir el riesgo de fractura y el umbral de tratamiento, como FRAX, en el que el beneficio de dar medicamentos sea superior al riesgo de no darlo, se basa en poblaciones específicas donde se han realizado estudios de fármaco-economía que contemplan costos de tratamientos estándar de primera línea para osteoporosis (alendronato), costos de tamización con densitometría, costos de manejo de fracturas y costos que el sistema de salud pública se puede permitir pagar para cada patología, entre otros factores.

De esta manera se define un umbral de tratamiento por edad, que sea costoefectivo y que por definición, es variable para cada país. Colombia no dispone de dichos estudios, por lo cual no se puede asumir que los costos que la salud pública puede pagar en países del primer mundo, sean los mismos para países en vías de desarrollo, esto si se considera el supuesto de que la población de cualquier lugar del mundo tiene el mismo riesgo de fractura modificado con el mismo impacto por los factores clínicos conocidos ampliamente, lo cual aparentemente no es cierto, pues algoritmos como FRAX se calculan con bases poblacionales específicas de cada país.

Ese es otro punto importante que se debe considerar: la población colombiana que se tiene en cuenta en FRAX.

Debemos mirar si esos datos son aplicables a la totalidad de Colombia; son datos tomados de Barranquilla, ciudad a nivel del mar que puede tener algunos factores protectores de osteoporosis por su situación geográfica y que explicarían el bajo riesgo de fractura que tiene Colombia en diferentes publicaciones, que no necesariamente se correlacionan con la clínica que se observa en consulta (pacientes en corticoterapia crónica con fracturas de bajo impacto y densidad mineral ósea no tan baja, etc.). 
Por último, quisiera poner en consideración la existencia de otros algoritmos que predicen baja densidad ósea y, por ende, riesgo de fractura que han demostrado tener un desempeño similar o no inferior que FRAX y que son menos dispendiosos de usar, lo cual podría a conducir a que los médicos de atención primaria consideren los factores de riesgo clínico de más impacto en Colombia, con más facilidad, para definir quién requiere estudios más amplios y tratamientos oportunos.

Encuentro con el experto ¿Cuándo medir y tratar la deficiencia de vitamina $\mathrm{D}$ en adultos?

\section{Dr. Oscar Rosero Olarte}

Especialista en Medicina Interna y Endocrinología,

Universidad Militar Nueva Granada

Fiscal Médico, Asociacion Colombiana de Endocrinología

Secretario, Asociación Colombiana de Osteoporosis y Metabolismo Mineral, ACOMM

Director Médico, Instituto de Osteoporosis de los Llanos

Fundador Asociación de Diabetes del Llano

T a principal función de la vitamina D está relacionada con el Umetabolismo del calcio, la falta de vitamina D en niños produce raquitismo y en adultos, osteomalacia. Desde que se descubrió que le receptor de vitamina D (VDR) se encuentra en casi todos los tejidos y que la enzima $1 \alpha$ hidroxilasa necesaria para la activación final de la vitamina $\mathrm{D}$ también se encuentra ampliamente distribuida, se hace obvio que la vitamina $\mathrm{D}$ tenga una gran cantidad de funciones en otros sistemas diferentes al esquelético.

De esta forma, los bajos niveles de 25-hidroxivitamina D (25(OH) D) se han asociado a enfermedades como cáncer, diabetes, enfermedad coronaria, infecciones, enfermedades autoinmunes, caídas y alteraciones cognitivas.

Esto ha creado un gran interés en la vitamina D, en Pubmed el número anual de publicaciones relacionadas suman más de 20.000, con más de 180 metanálisis publicados; sin embargo, a pesar de toda esta avalancha de información, aún existen áreas sobre las que debemos profundizar, como lo es el conocimiento de que se considera una concentración suficiente de vitamina D más allá de la prevención del raquitismo.

Aunque no hay consenso con respecto a los niveles séricos óptimos de 25(OH) vitamina D, la deficiencia se define, de acuerdo con la guía de la Sociedad Americana de Endocrinología, como un nivel sérico inferior a $20 \mathrm{ng} / \mathrm{mL}$ (50 nmol/L). En general, un nivel de 25(OH) D de 21 a $29 \mathrm{ng} / \mathrm{mL}$ (52 a 72 nmol/l) puede ser considerado como una insuficiencia relativa de vitamina D y un nivel por encima de $30 \mathrm{ng} / \mathrm{mL}$ se puede considerar como adecuado. Sin embargo, existe poca certeza sobre el riesgo de niveles séricos elevados de 25(OH) D.
La razón para preferir la medición de $25(\mathrm{OH})$ D es que es fácil de medir, es más abundante y estable con una vida media más larga que su metabolito activo la 1-25-dihidroxivitamina D $\left(1,25 \mathrm{OH}_{2} \mathrm{D}\right)$ y se correlaciona mejor con la supresión de la PTH, en pacientes bajo tratamiento.

En caso de iniciar suplementación, el tiempo recomendado para medir los niveles de 25(OH) D es tres meses. Aunque se puede utilizar la dosificación PTH como un indicador temprano de respuesta a la terapia.

\section{¿Cómo están los niveles de vitamina D en la población colombiana?}

En este sentido se han publicado tres estudios clínicos. El primer estudio publicado de insuficiencia de vitamina D en Colombia fue realizado en la clínica Fundación Santa Fe de Bogotá, institución de cuarto nivel de atención. Se encontró para las mujeres una media de 30,5 ng/mL de $25(\mathrm{OH}) \mathrm{D}$, en el 69,5\% (73/105) de los sujetos del estudio se documentó algún tipo de insuficiencia, siendo moderada (8-19 $\mathrm{ng} / \mathrm{mL}$ ) en el $23,8 \%$ de la población analizada, y no hubo diferencia significativa entre hombres y mujeres.

Un segundo estudio realizado en la ciudad de Medellín (Colombia), en 205 mujeres con diagnóstico de osteopenia $\mathrm{u}$ osteoporosis, tomando como punto de corte niveles de 25 $(\mathrm{OH})$ D para suficiencia por encima de $30 \mathrm{ng} / \mathrm{mL}$, encontró un promedio de $26,7 \mathrm{ng} / \mathrm{mL}$, siendo insuficiente $(20,1-29 \mathrm{ng} / \mathrm{mL})$ en el $55,1 \%$ de las pacientes estudiadas y deficiente $(<20 \mathrm{ng} /$ $\mathrm{mL}$ ) en el $16,6 \%$.

También en la ciudad de Medellín (Colombia) se realizó un tercer estudio, se analizaron 113 mujeres, de las cuales 40 se encontraban en menopausia de 45 a 55 años y 33 posmenopáusicas $>65$ años. El 77,5\% del grupo de las mujeres menopáusicas y el $69,7 \%$ de las mujeres mayores de 65 años tenía niveles de $25(\mathrm{OH}) \mathrm{D}<$ de $25 \mathrm{nmol} / \mathrm{L}(10 \mathrm{ng} / \mathrm{mL})$.

Un cuarto estudio, esta vez realizado en la ciudad de Villavicencio, en 116 mujeres posmenopáusicas, se encontró que en las mujeres menores de 60 años la media de vitamina $D$ fue $30,23 \mathrm{ng} / \mathrm{mL}(\mathrm{SD}=11,6)$, mientras que en las mayores de 60 años se registró un promedio de $28,5 \mathrm{ng} / \mathrm{mL}(\mathrm{SD}=8,9)$; apenas $39,6 \%$ de las mujeres valoradas tenía niveles normales, se encontró un porcentaje elevado de mujeres con insuficiencia de la vitamina $(39,62 \%)$ y con déficit franco $(20,75 \%)$.

\section{¿En quién se debe medir la vitamina D?}

La Endocrine Society recomienda medir en individuos en riesgo de sufrir déficit, no se recomienda hacer tamizaje en población de bajo riesgo de déficit. Las personas con riesgo de déficit están listadas en la tabla 1.

\section{Dosis recomendadas para la suplementación}

Niños menores de 1 año deben ser suplementados con 400 UI día, de 1-18 años 600 UI día, y para pacientes entre 19 y 50 años se recomienda un aporte diario de $600 \mathrm{UI}$; por encima de los 50 años, 800 UI día. En mujeres embarazadas se requiere de 1.500-2.000 UI/día para mantener los niveles por encima de $30 \mathrm{ng} / \mathrm{dl}$. A niños y adultos que toman medicamentos an- 
Tabla 1. Indicaciones para medición de 25(OH) D

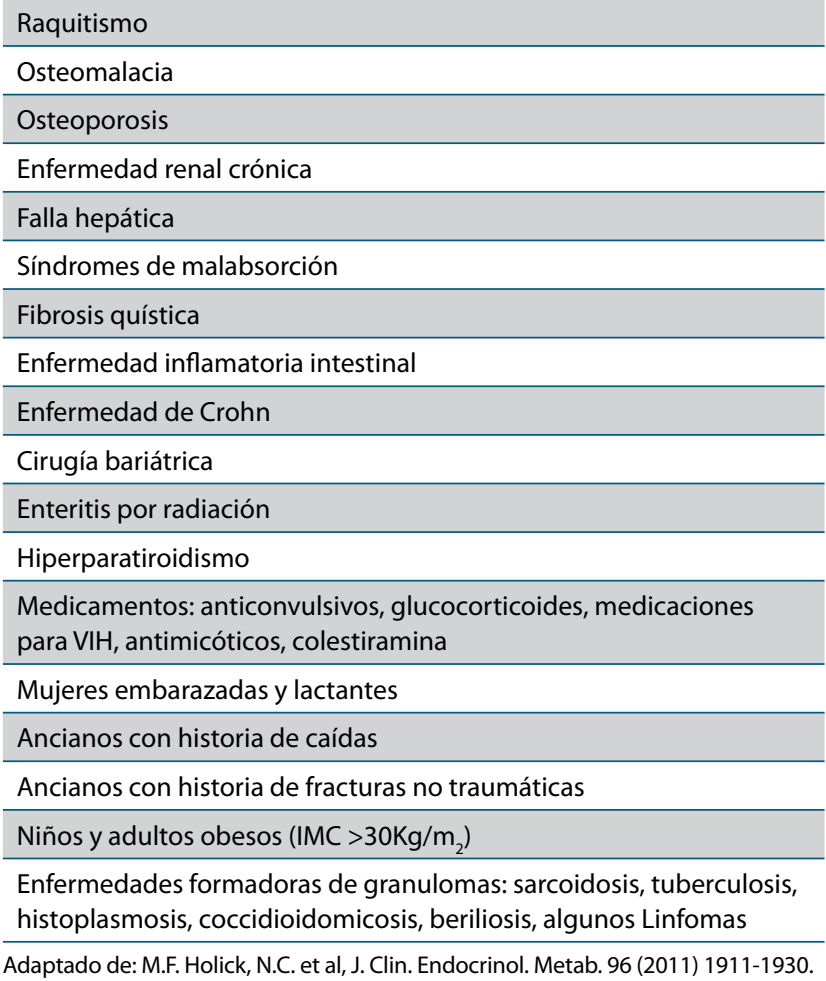

ticonvulsivos, glucocorticoides, antimicóticos y medicaciones para VIH se les debe administrar 2 a 3 veces más vitamina $D$ que a las personas de su grupo de edad. Las personas obesas deben recibir el doble de la recomendación para su misma edad.

\section{Suplementación en caso de deficiencia de vitamina $\mathbf{D}$}

Niños menores de 18 años con déficit de vitamina $D$ deben recibir 2.000 UI día durante 6 semanas, hasta lograr niveles deseados con una dosis de mantenimiento posterior de $400 \mathrm{a}$ 1.000 UI día.

Adultos con déficit deben recibir 6.000 UI día durante 8 semanas, una vez alcanzada la meta continuar con suplencia de 1.000 UI a 2.000 UI/día.

Pacientes obesos, o que toman medicamentos que afectan el metabolismo de la vitamina D, o con malabsorción intestinal, pueden requerir de 6.000 UI a 10.000 UI día, con monitoreo de los niveles de $25(\mathrm{OH}) \mathrm{D}$ y ajuste de dosis. 